\title{
Mechanical Properties of Phenolic Foam Modified Insulation Board by Urethane Oligomer
}

\author{
Guo-Zhong LU'1 , Wei-Xuan ZHAO ${ }^{1}$, Yi-Xun LV², Xiu-Juan DING ${ }^{2, a, *}$ \\ ${ }^{1}$ Engineering Technology Research Center of passive low energy building, Beijing100041 \\ ${ }^{2}$ Beijing Building Materials Academy of Sciences Research, State Key Laboratory of Solid Waste \\ Reuse for Building Materials, Beijing100041 \\ adingxiujuanlove@126.com \\ ${ }^{*}$ Corresponding author
}

Keywords: Phenolic Foam, Polyurethane, Mechanical properties.

\begin{abstract}
In this paper, the major research contents include improving the properties of phenolic foams through making urethane oligomer modifiers. Various characterization methods were adopted to analyze the properties and microstructure of phenolic foams. Finally, a new type of phenolic foam, which has good insulation effect and excellent mechanical properties, has been made. The results have shown that this new phenolic foam has these features of good insulation effect (thermal conductivity is $0.030 \mathrm{~W} / \mathrm{m} \bullet \mathrm{K}$ ), good hardness (apparent density can reach $40-60 \mathrm{~kg} / \mathrm{m} 3$ ), and high toughness (the flexural strength can reach to $4.0 \mathrm{~N} / \mathrm{cm} 2$, and the compression strength can be improved by $16 \%$ and reach to $0.134 \mathrm{Mpa}$ ). These phenolic foams can be widely used in construction field of external wall insulation, which is significant to building energy conservation.
\end{abstract}

\section{Introduction}

As the energy issue has been attracting worldwide attention, the country and the localities have enacted a series of code on energy saving design for buildings ${ }^{[1,2]}$. As a result, organic insulation materials with desirable thermal insulation property and low prices (such as polystyrene foam, EPS, XPS, etc.) have been widely used in the thermal insulation of civil and public buildings. Although energy conservation has been solved effectively, great hidden fire hazards are brought about accordingly. The frequent occurrence of numerous great fires ${ }^{[1]}$ leads to huge socio-economic losses, heavy casualties and environmental pollutions. For this reason, the development of a new type of flame resistant and thermal insulation material has become the major topic that needs to be addressed without delay. Phenolic foam is a new generation of energy-saving and fireproof material. When sprayed by flame of $1700^{\circ} \mathrm{C}$ for ten minutes, the material will show a surface carbonization and will not be burnt through. Characterized by such advantages as noninflammability and favorable heat insulation effect, phenolic foam has become the most ideal ${ }^{[2]}$ thermal insulation material of building external walls. But such defects of the material as high brittleness, prone to pulverization and low strength during construction prevent it from coming into extensive use ${ }^{[3]}$. Targeted at the deficiencies of its property, we have carried out a series of researches ${ }^{[3]}$.

There is research indicating that MDI type of polyurethane prepolymer will toughen phenolic foam and reduce its pulverization degree. But as a result of the high reaction activity of this material and its low compatibility with phenolic resin, the production and application of MDI type of polyurethane prepolymer have been restricted. This paper revolves around the modified preparation of polyurethane prepolymer to obtain polyurethane modifier, which will react with liquid phenolic resin. By applying a large number of flexible molecules in the rigid phenolic resin groups, phenolic foam with excellent tenacity will be produced by means of foaming. 


\section{Experiment}

\section{Material of Experiment}

Phenolic resin, industrial grade, Shandong Jinan Shengquan Group Co., Ltd.; Acid curing agent, industrial grade, Shandong Jinan Shengquan Group Co., Ltd.; Polyurethane prepolymer, industrial grade, Yantai Wanhua Polyurethane Co., Ltd.; Acetone, analytically pure, Tianjin Damao Chemical Regent Factory; Tween-80, analytically pure, Tianjin Kaitong Chemical Regent Co., Ltd.; N-pentane, analytically pure, Tianjin Damao Chemical Regent Factory.

\section{Analytical and Testing Instruments}

Microcomputer control electron universal testing machine, WDW3000, Changchun Kexin Experimental Instrument Co., Ltd.; Lab dispersion machine, DYF400W, Shanghai Deyu E\&M Development Co., Ltd.; Electrothermal blowing dry box, DHG-9053A, Guangzhou Huruiming Instrument Co., Ltd.; Infrared spectrometer (FTIR), 8400S, Shimadzu; Scanning electron microscope, S-3400, Hitachi; Thermal gravimetric analyzer, TGA Q50, Waters Corporation.

\section{Preparation of Polyurethane Modifier}

Put polyurethane and acetone in a closed container based on the mass ratio of 3:1. When the temperature of water bath reaches $70^{\circ} \mathrm{C}$, mix them to react for ten minutes. After raising the temperature to $80^{\circ} \mathrm{C}$, quickly mix them to react for 15 minutes to obtain polyurethane modifier.

\section{Preparation of Phenolic Foam}

Add 2 to 8 units of polyurethane modifier to 100 units of phenolic resin and quickly mix them evenly at normal temperature through electrical stirring. Add 4 units of foam stabilizer (Tween-80) and 12 units of foaming agent (n-pentane) to the mixture and mix them in high speed once more. Finally add 9 units of acid curing agent to the mixture and then mix it in high speed. When the foam turns white, immediately pour it into the preheating mould coated with release agent for foaming, mould filling and moulding. After the moudling process, put the phenolic foam into the oven for a continuous ripening at $70^{\circ} \mathrm{C}$ for two hours.

\section{Performance Test}

Test the sample's apparent density in accordance with GB/T6343-1995; Test the sample's compression strength in accordance with GB/T8813-2008 compression test methods on rigid foamed plastics; Test the sample's bending strength in accordance with GB/T9341-2008; Test the sample's water absorption in accordance with GB/T8810-2005; Test the sample's heat conductivity coefficient in accordance with GB/T10294-2008; Test the sample's dimensional stability in accordance with GB/T8811-2008, etc.

\section{Conclusion and Discussion}

\section{Effects of the Use Level of Curing Agent on Properties of Insulation Board}

The use level of acid curing agent is an important parameter that affects the properties of phenolic insulation board. When the use level of acid curing agent is a little on the low side, effective catalysis cannot be achieved on the foaming process of the phenolic insulation board. Instead, few foam and collapsed foam are likely to be caused on the phenolic insulation board. When too much curing agent is being used, stronger catalysis shall be caused, which is likely to result in uncontrollable strong foaming on the phenolic insulation board and thus reduce the hardness of foam. Generally, 8 to 12 
grams of phenolic insulation board shall be used for foaming. Given the composite economic results, the use level of curing agent for the phenolic insulation board shall be $8 \%, 9 \%$ and $10 \%$ respectively (corresponding to the mass of phenolic resin). Testing the apparent density of phenolic insulation board to show its hardness, the compression strength to show its tenacity as well as the exploration on effects of the use level of acid curing agent on the properties of phenolic insulation board are shown in Table 1 listed below.

Tab.1 Effects of the Use Level of Curing Agent on Properties of Phenolic Foams

\begin{tabular}{ccc}
\hline Use level of curing agent(\%) & Apparent density $\left(\mathrm{kg} / \mathrm{m}^{3}\right)$ & Compression strength (Mpa) \\
\hline 8 & 37.39 & 0.095 \\
9 & & 0.115 \\
10 & 37.47 & 0.086
\end{tabular}

As shown in Table 1, when the use level of acid curing agent is $9 \%$, the phenolic insulation board presents the highest tenacity and the compression strength will be $0.115 \mathrm{Mpa}$. Consequently all the following experiments shall be finished when the use level of curing agent is $9 \%$.

\section{Effects of Polyurethane Modifier on the Apparent Density and Compression Strength of Foam}

Prepare the use level of polyurethane modifier as $0 \%, 2 \%, 4 \%, 6 \%$ and $8 \%$ respectively (corresponding to the mass of phenolic resin). Add the polyurethane modifier to the phenolic resin to mix them evenly for foaming. Test the effects of the use level of polyurethane modifier on the apparent density and compression strength of phenolic foam.

Tab.2 Effects of the Use Level of Polyurethane Modifier on the Apparent Density of Phenolic Foam

\begin{tabular}{cc}
\hline Use level of polyurethane modifier(\%) & Apparent density $(\mathrm{kg} / \mathrm{m} 3)$ \\
\hline 0 & 37.47 \\
2 & 46.04 \\
4 & 44.47 \\
6 & 32.04 \\
8 & 37.57 \\
\hline
\end{tabular}

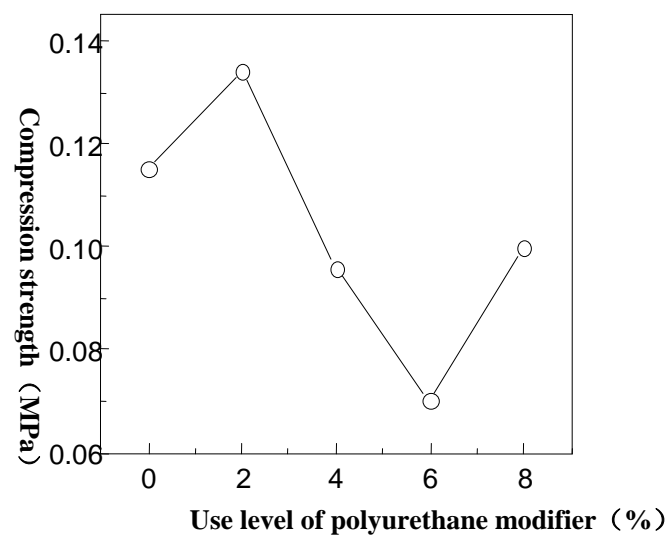

Fig.1 Effects of the Use Level of Polyurethane Modifier on the Compression Strength of Phenolic Foam 
As shown in Table 2 and Fig.1, when $2 \%$ polyurethane modifier is added, the apparent density of phenolic foam reaches the maximum value, i.e. $46.04 \mathrm{~kg} / \mathrm{m} 3$, showing an increase of $22.9 \%$ compared with the blank group. At the same time, the compression strength of phenolic foam reaches the maximum value, i.e. $0.134 \mathrm{MPa}$, showing an increase of $16.5 \%$ compared with the blank group. Thus it can be seen that when $2 \%$ polyurethane modifier is being added, the compression strength of phenolic foam reaches the maximum, that is, the highest tenacity. This indicates that small amounts of polyurethane modifier can effectively increase the tenacity of phenolic foam. The reason for this is that the isocyanate in the polyurethane modifier and the hydroxymethyl in the phenolic resin form a cross-linking reaction, which gives rise to interpenetrating network structure. The generation of a large quantity of flexible carbamate segments changes the rigid structure of phenolic resin and thus increases the compression strength and tenacity of phenolic foam. However, as the use level of modifier increases, a more crosslinked structure will be formed, making the foaming process more and more difficult and the physical properties of phenolic foam on the decline ${ }^{[4]}$.

\section{Effects of Polyurethane Modifier on the Bending Strength of Foam}

If the foam material shows bending deflection due to the action of force, the material itself will simultaneously undergo compression stress and tension stress. Whether the two stresses are dispersed or not determines the tenacity of phenolic foam. The exploration results on the effects of different use levels of modifier on the bending strength of foam are shown in Fig.2 listed below.

As shown in Fig.2, the foam's bending strength increases and then decreases as the use level of polyurethane modifier increases. The adding of polyurethane modifier can increase both the compression strength and the tensile strength. Hence its loading force, that is, the bending strength, will increase. When $2 \%$ polyurethane modifier is being added, the foam's bending strength reaches the maximum. When polyurethane modifier of over $2 \%$ is being added, the crosslinking degree of the phenolic foaming system becomes difficult and the obtained foam material shows nonuniform and incompact bubbles. At that time, the foam structure affects a great deal to the compression strength, thus causing the bending strength to decrease.

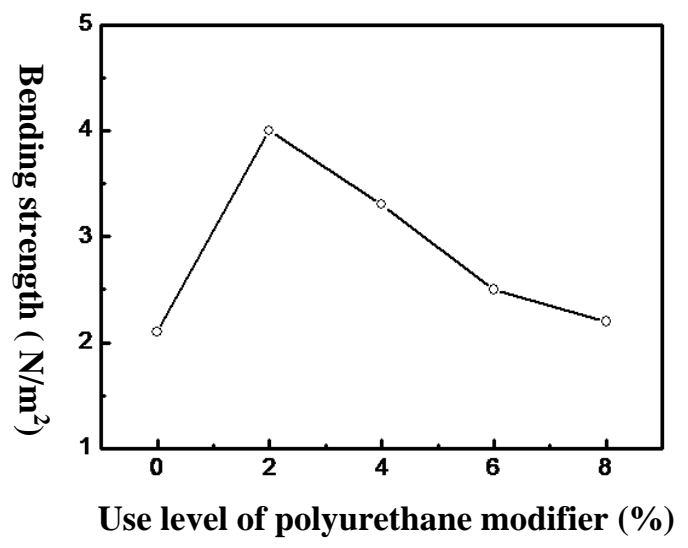

Fig.2 Effects of Use Level of Polyurethane Modifier on the Bending Strength of Phenolic Foam

\section{Thermogravimetric Analysis}

Fig. 3 is the thermogravimetric curve for pure phenolic foam and strengthened phenolic foam by polyurethane modifier. Add 2\% polyurethane modifier to the phenolic resin to prepare phenolic foam and then compare it with the unmodified phenolic foam. Find out the modification effect of polyurethane modifier on the phenolic resin. It is shown in the figure that phenolic foam shows great heat resistance. The decomposition temperature of pure phenolic foam is lower than $350^{\circ} \mathrm{C}$, whereas 
the decomposition temperature of strengthened phenolic foam by polyurethane modifier ranges from 350 to $400^{\circ} \mathrm{C}$, so the heat stability of the modified phenolic foam has been improved.

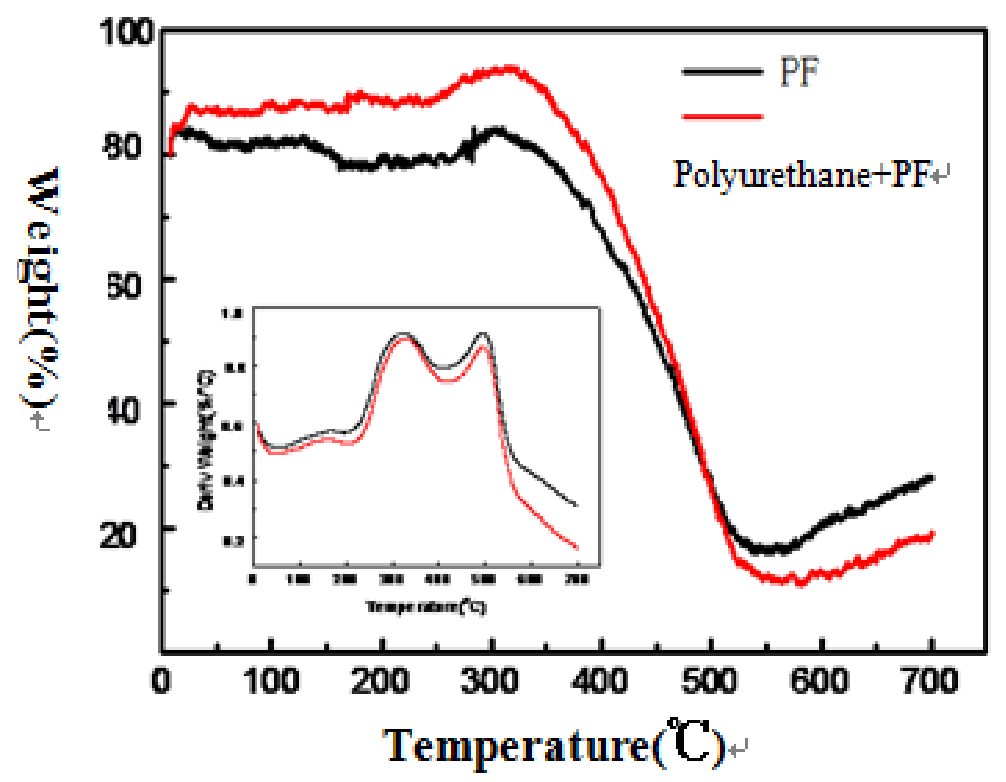

Fig.3 Thermogravimetic Analysis and Comparison of Modified Phenolic Foam by Polyurethane Modifier and Ordinary Phenolic Foam

\section{Infrared Spectroscopic Analysis}

Fig.4 shows the infrared spectrogram of pure phenolic foam and the infrared spectrogram of the modified phenolic foam by $2 \%$ polyurethane modifier. It can be seen from the figure that at the point of $1600-1450 \mathrm{~cm}^{-1}$, the oscillating peak is the $-\mathrm{C}=\mathrm{C}$ - peak on the benzene ring. At the point of $3016.97 \mathrm{~cm}^{-1}$, the fluctuation is the $\mathrm{C}-\mathrm{H}$ absorption peak on the benzene ring. According to the absorption peak of $3436-3350 \mathrm{~cm}^{-1}$, the width of the absorption peak of the modified phenolic foam therein will increase, which indicates the polyurethane modifier and phenolic resin have reacted and will increase the tenacity of phenolic foam to some extent ${ }^{[5]}$.

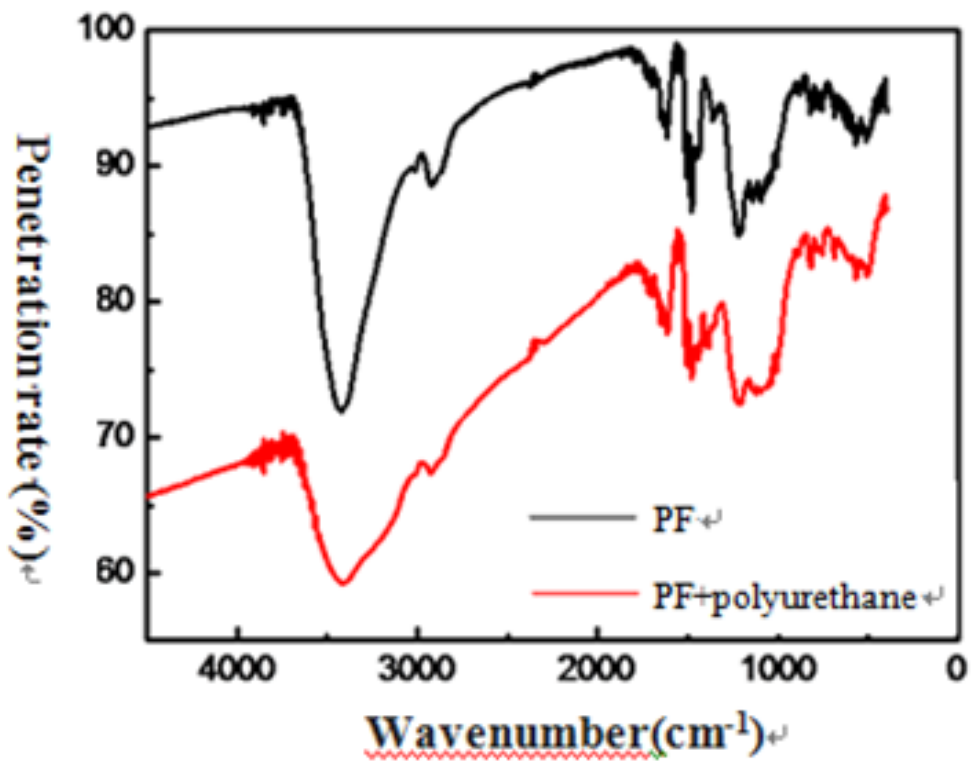

Fig.4 Infrared Spectrogram of Strengthened Phenolic Foam by Polyurethane Modifier 


\section{Cellular Structure of Polyurethane Modified Phenolic Foam}

Foam is made up of a large number of micro bubbles. When the foam structure is affected by addition of enhancer, changes in macroscopic aspects ${ }^{[6-12]}$ such as compression property and heat stability will inevitably be shown. Fig. 5 is the microstructure of the bubbles of the modified phenolic foam. It can be seen from the figure that the bubbles are in the shape of diamond and some bubble structures have burst; bubbles are closely connected and evenly distributed. Desirable bubble structure means ideal thermal insulating property, which also accounts for the higher compression and thermal stability of the polyurethane modified phenolic foam.
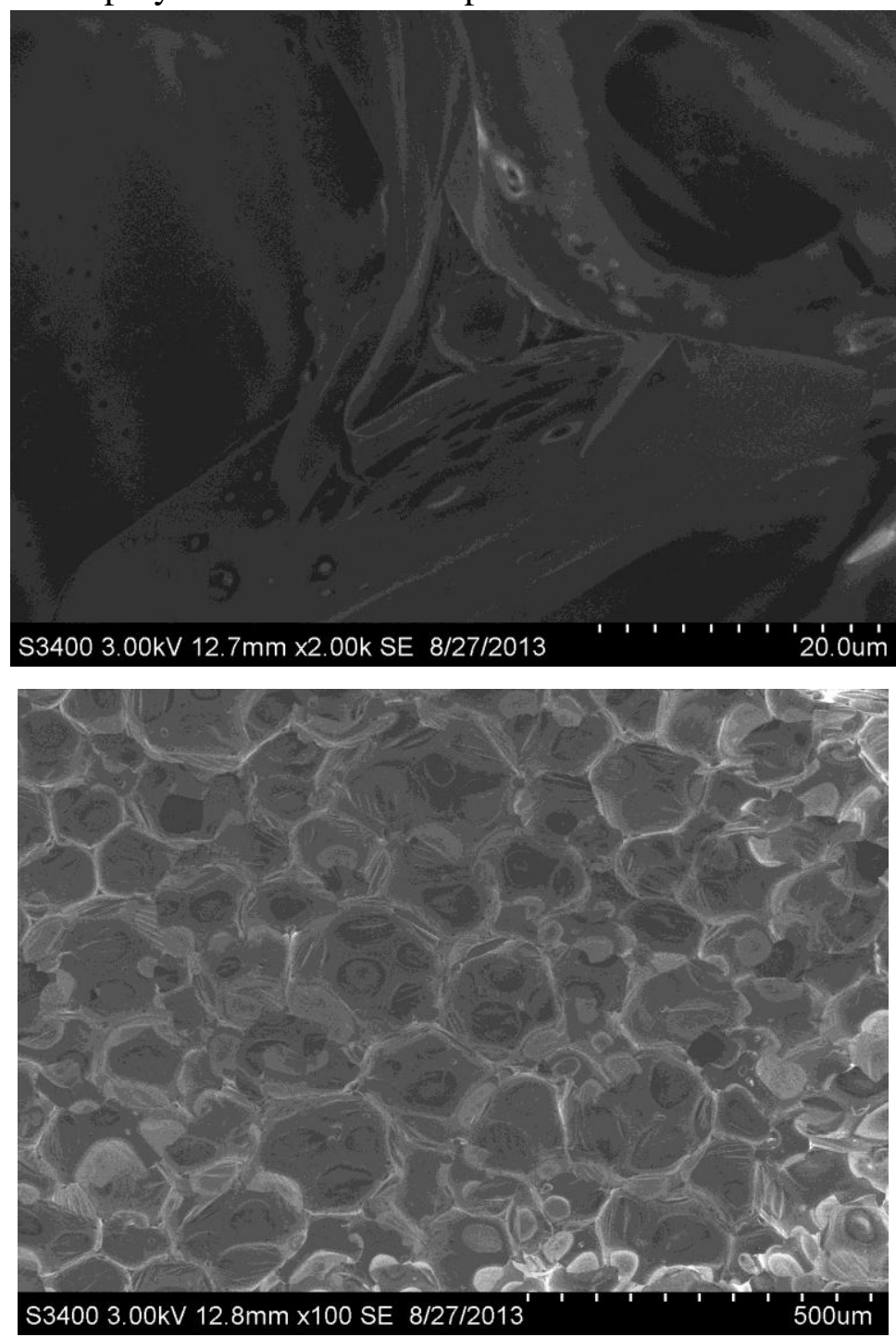

Fig.5 SEM Image of Polyurethane Modified Phenolic Foam

\section{Analysis of Comprehensive Properties of Modified Phenolic Foam}

According to the above experimental results, phenolic foam can be modified by adding $2 \%$ polyurethane modifier, that is, phenolic foam with compression property up to $0.134 \mathrm{MPa}$ can be obtained. Table 3 shows the main performance parameters for the phenolic insulation board obtained under such conditions. In comparison with the requirements of the national standard GB/T20974-2007 Thermal Insulated Phenolic Foam Products (PF), all the parameters indicate that all the indicators of the modified phenolic have surpassed the national standard and the modified phenolic exhibits excellent fire resistance and thermal insulation. 
Tab.3 Main Performance Indicators of Phenolic Foam

\begin{tabular}{|c|c|c|c|}
\hline Item & Performance index & $\begin{array}{l}\text { National } \\
\text { standard }\end{array}$ & Testing standard \\
\hline Apparent density $\left(\mathrm{kg} / \mathrm{m}^{3}\right)$ & 40-60(adjustable) & 40 & GB/T6343-2009 \\
\hline Bending strength $\left(\mathrm{N} / \mathrm{cm}^{2}\right)$ & 4.0 & / & GB/T9341-2008 \\
\hline $\begin{array}{c}\text { Tensile strength perpendicular } \\
\text { to surface }(\mathrm{kpa})\end{array}$ & 140 & I & JG149-2003 \\
\hline Water absorption $\%$ & 5.3 & $\leq 7.5$ & GB/T8810-2005 \\
\hline $\begin{array}{l}\text { Dimensional stability } \% \\
\qquad\left(70^{\circ} \mathrm{C} \pm 2^{\circ} \mathrm{C}, 48 \mathrm{~h}\right)\end{array}$ & 1.0 & $\leq 2$ & GB/T8811-2008 \\
\hline Compression strength (MPa) & 0.134 & $\geq 0.10$ & GB/T8813-1988 \\
\hline Oxygen index & $40 \%$ & I & GB/T2406.2-2009 \\
\hline $\begin{array}{l}\text { Heat conductivity coefficient } \\
\mathrm{W} /(\mathrm{m} \cdot \mathrm{K})\end{array}$ & 0.030 & $\leq 0.035$ & GB/T10294-2008 \\
\hline
\end{tabular}

\section{Experimental Conclusion}

This paper revolves around the design of polyurethane modifier to modify phenolic insulation board. Multiple testing analysis methods have been adopted to show the modifier's modification effects on phenolic foam. The main conclusions are presented as follows.

1. Polyurethane modifier shows remarkable effect in improving the tenacity of phenolic insulation board. When only $2 \%$ polyurethane modifier is being applied, the compression strength of modified phenolic foam comes up to $0.134 \mathrm{MPa}$, and bending strength, $4.0 \mathrm{~N} / \mathrm{cm}^{2}$.

2. The infrared analysis indicates that the combination of polyurethane modifier and phenolic resin changes the group structure of phenolic resin. The thermogravimetric analysis shows that the heat stability of the modified phenolic insulation board has been improved. The image of the microstructure of phenolic insulation board obtained via electric mirror shows that the modified phenolic insulation board has perfect cellular structure and favorable thermal insulating property.

3. All the indicators of the polyurethane modified phenolic foam have surpassed the national standards and the modified phenolic foam exhibits excellent fire resistance and thermal insulation as well as exceptional superior tenacity (surpassing industrial standard by $12 \%$ ).

This product addresses the technical problem of the high brittleness and low strength typical of phenolic foam, and gives full play to its advantageous fire resistance and thermal insulation property. Thus it effectively solves the issue of fire safety of the external thermal insulation system of the present building external walls of China, realizes the "double security" of thermal insulation \& energy saving and safety of buildings, raises the energy-saving efficiency of buildings in China, the technical level of the energy-saving efficiency of buildings in China and China's residence environment quality and boosts the rapid development of China's new thermal insulation materials for walls.

\section{References}

[1] KANG Wusheng, Research and Application of Phenolic Foam, a New Thermal Insulation Material for External Walls [J]. 2013, (2): 168-169. 
[2] Research Institution for Standard Rating under the Ministry of Construction, RISN-TG001-2005, Guidelines on Insulation Technology for Building External Walls [S]. Beijing, China Building Industry Press, 2005.

[3] C Kaynak, O Cagatay. Rubber Toughening of Phenolie Resin by Using Nitrile Rubber and Amino Silane [J]. Polylner Testing, 2006, 25(3): 296-305.

[4] M S. Yun, W I Lee. Analysis of Bubble Nucleation and Growth in the Pultrusion Process of Phenolic Foam Composites [J]. Compos Sci Technol, 2008, 68(1): 202-208.

[5] YUN Hongzhi, JIANG Zhiguo, Research on the Properties of Glutaraldehyde Modified Phenolic Resin and Foamed Plastic [J]. New Chemical Materials, 2009, 37(3):100-102. 